Portland State University

PDXScholar

5-8-1992

\title{
A Comparison of Grammatical Morpheme Usage by Four Year Olds With Normal, Impaired, and Late Developing Language
}

Sally Alforde

Portland State University

Follow this and additional works at: https://pdxscholar.library.pdx.edu/open_access_etds

Part of the Speech and Hearing Science Commons

Let us know how access to this document benefits you.

Recommended Citation

Alforde, Sally, "A Comparison of Grammatical Morpheme Usage by Four Year Olds With Normal, Impaired, and Late Developing Language" (1992). Dissertations and Theses. Paper 4244.

https://doi.org/10.15760/etd.6128

This Thesis is brought to you for free and open access. It has been accepted for inclusion in Dissertations and Theses by an authorized administrator of PDXScholar. Please contact us if we can make this document more accessible: pdxscholar@pdx.edu. 
AN ABSTRACT OF THE THESIS OF Sally Alforde for the Master of Science in Speech Communication: Speech and Hearing Sciences presented May 8, 1992.

Title: A Comparison of Grammatical Morpheme Usage by Four Year Olds With Normal, Impaired, and Late Developing Language.

APPROVED BY THE MEMBERS OF THE THESIS COMMITTEE:

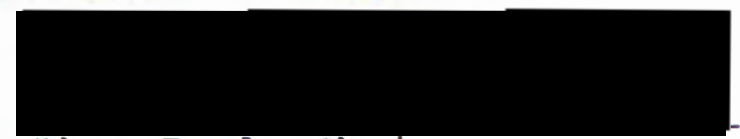

Rhea Paul, Chair
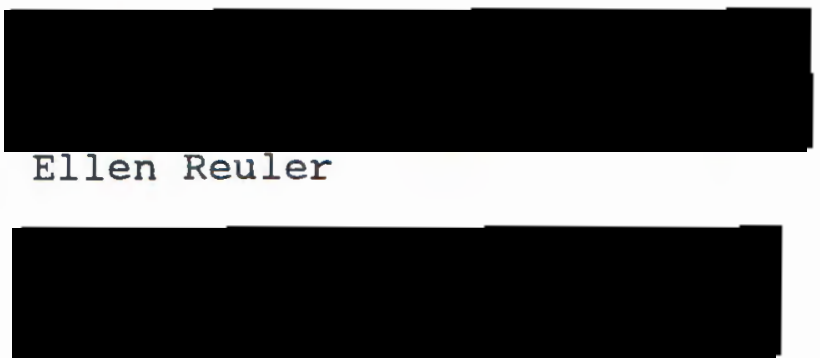

Ruth Falco

The purpose of this study was to determine whether language-disordered four-year-old children and those with a history of language delay but currently normal functioning would have acquired a significantly lower percentage of 13 grammatical morphemes than children of the same age with normal language skills. Research has shown that there is a consistency of order in which these 
morphemes are acquired in children with normal language ability. Studies have also shown that while languagedisordered children acquire these grammatical morphemes in a similar order, the process is slowed down. Languagedisordered children have difficulty with grammatical morpheme development. Not found in the research is information regarding grammatical morpheme development for children with normal language skills but a history of language delay. Does grammatical morpheme development still pose a problem for these children? Is grammatical morpheme development for this population consistent in terms of order of acquisition with normal and languagedisordered children? Does acquisition of these morphemes still show deficiencies when language skills have progressed into the normal range? Do patterns of grammatical morpheme development demonstrate distinct features for these children? These are the questions that the present investigation sought to answer.

The sample for this study comprised 57 4-year-old children participating in a longitudinal study at Portland State University. They were divided into three groups:

(1) children with normal language skills, (2) a history of expressive language delay (HELD), and (3) expressive language disordered (ELD). Language samples were 
obtained for each subject while engaged in play with their mother. The samples were transcribed and entered into a computer at which time the SALT (Miller \& Chapman, 1985) program calculated MLU for group placement. Percentage of usage of the grammatical morphemes in obligatory contexts was then determined, again employing SALT. Where necessary, percentages were totalled by hand. An analysis of variance was then performed using SYSTAT. The results showed four morphemes to be significant at the .03 level-irregular third person singular, uncontractible copula, and contractible and uncontractible auxiliary be.

Investigation of the data suggests that there is a uniformity in order of acquisition of the grammatical morphemes similar to past research and percentage of usage of these morphemes for the HELD group was larger than the ELD group but smaller than the normal group. This indicates that while children with a history of language delay have progressed into the normal range for sentence length as indexed by MLU, they still have difficulty with grammatical morpheme development. In conclusion, these results suggest that children with a history of language delay but who are currently normal functioning do lie on a continuum of language ability between language-disordered and normal children. 
A COMPARISON OF GRAMMATICAL MORPHEME USAGE BY FOUR YEAR OLDS WITH NORMAL, IMPAIRED, AND LATE DEVELOPING LANGUAGE

by

SALLY ALFORDE

A thesis submitted in partial fulfillment of the requirements for the degree of

\author{
MASTER OF SCIENCE \\ in \\ SPEECH COMMUNICATION: \\ SPEECH AND HEARING SCIENCES
}

Portland state University

1992 
TO THE OFFICE OF GRADUATE STUDIES:

The members of the committee approve the thesis of Sally Alforde presented May 8, 1992.

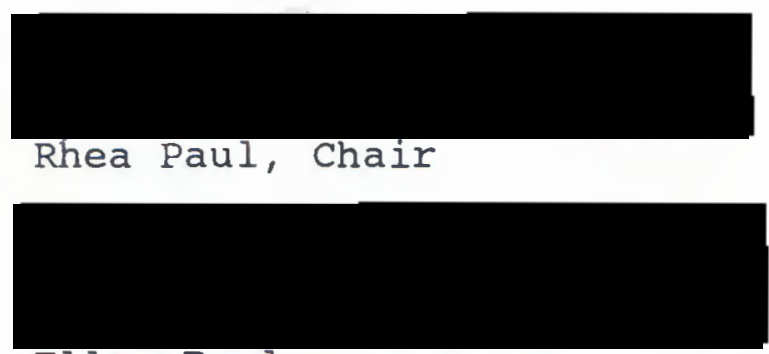

Ellen Reuler

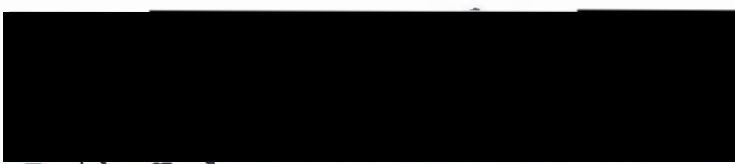

Ruth Falco

\section{APPROVED :}

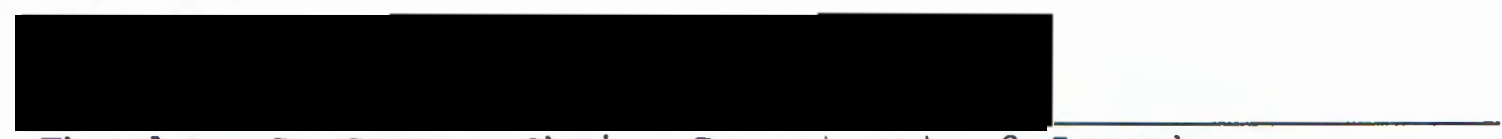

Theodore G. Grove, Chair, Department of Speech Communication

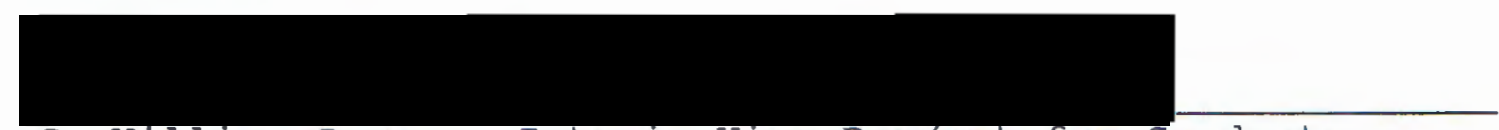

C. William Savery, Interim Vice Pcojost for Graduate studies and Research 


\section{ACKNOWLEDGEMENTS}

I wish to thank the members of my thesis committee: Ellen Rueler, Ruth Falco, and especially Dr. Rhea Paul for her advice and support.

I would also like to thank my husband, Nicholas, who, having been through the process himself, encouraged me with empathy and unwavering patience. 
TABLE OF CONTENTS

PAGE

ACKNOWLEDGEMENTS . . . . . . . . . . . . . . . . iii LIST OF TABLES . • . . . . . . . . . . . . . . . . vi v

CHAPTER

I INTRODUCTION AND STATEMENT OF PURPOSE . . . 1

Introduction . . . . . . . . . . . 1

Statement of Purpose . . . . . . . 3

Definition of Terms . . . . . . 5

II REVIEW OF THE LITERATURE . . . . . . . . 9

Grammatical Morphemes . . . . . 10

Normal Development

Delayed Development

Relationship of Phonology to

Morphological Development

Summary • . . . . . . . . . . 22

III METHODS AND PROCEDURES . . . . . . . . 23

Subjects . . . . . . . . . . . 23

Recruitment

Age 2 Group Placement

Age 4 Group Placement

Instrumentation . . . . . . . . . 26

Procedures . . . . . . . . . 26

Data Analysis . . . . . . . . 27

Reliability 
IV

$$
\begin{aligned}
& \text { RESULTS AND DISCUSSION . • . . . . . . } 29 \\
& \text { Results . . . . . . . . . . } 29 \\
& \text { Discussion . . . . . . . . . . } 33
\end{aligned}
$$

REFERENCES

$$
\cdot \cdot \cdot \cdot
$$

APPENDICES

A

PARENTAL CONSENT FORM . . . . . . . .

B LANGUAGE DEVELOPMENT SURVEY . . . . . . . . 


\section{LIST OF TABLES}

TABLE

PAGE

I Brown's 14 Grammatical Morphemes in

Order of Acquisition . . . . . . . 12

II Brown's Stages of Preschool Language

Development • • • • • • • • • • • 15

III Summary of Demographic Data . . . . . . . 25

IV Group Placement Based on MLU . • . . . . . 26

$\mathrm{V} \quad$ List of Morphemes Acquired by

Experimental Groups . . . . . . . 30

VI Percentage of Usage of 13 Grammatical

Morphemes by Three Groups of Four-

Year-old Children . . . . . . . . 31

VII ANOVA • . . . . . . . . . . . . . . . 32

VIII Stage Assignment for Normal Grammatical

Morpheme Development . . . . . . . 34 
CHAPTER I

INTRODUCTION AND STATEMENT OF PURPOSE

INTRODUCTION

One of the tasks of speech-language pathologists is to assess language development in children. Assessment involves the examination of all aspects of language including expressive and receptive language abilities in phonology, semantics, syntax, and morphology. Morphology refers to the study of word organization. Words are comprised of one or more meaningful units called morphemes. Morphological development is an important part of language assessment because morphology is involved with the internal construction of words, adding meaning to words, and producing grammatical sentences. When children begin talking, they use basic word forms only, without morphological elaboration. As language development progresses, increases in morphological complexity represent an increase in linguistic knowledge which enables children to speak with greater specificity and sophistication.

Studies of normal language development have enabled researchers to identify 14 grammatical morphemes that are acquired (i.e., used correctly 90 percent of the time) in 
a fairly systematic order (Brown, 1973; devilliers \& devilliers, 1973). Further investigation of grammatical morpheme development has included language-disordered children (Kessler, 1975; Trantham \& Pederson, 1976; Johnston \& Schery, 1976). The results of these studies suggest grammatical morpheme development in language-disordered children is similar to normals in acquisition sequence, but slowed down. Language-disordered children acquire grammatical morphemes at a higher language level than normals as indexed by mean length of utterance (MLU) in morphemes. However, these studies have only investigated normal and language-disordered children's acquisition of the 14 grammatical morphemes. No comparison has been made between children with normal language, language disorders, and those with a history of language delay. The use of grammatical morphemes by children with a history of expressive language delay but currently normal functioning in terms of MLU is unknown. This group of children's language development raises some interesting questions. will their usage of grammatical morphemes lag behind their MLU when compared to normals as does the language disordered group? This would suggest that usage of grammatical morphemes is more difficult to increase than MLU. Or will their usage of grammatical morphemes present a different pattern of development? Information about the 
usage of grammatical morpheme development in children with a history of language delay will provide an interesting contrast to both language-disordered and normal-language children regarding the role of morphological development in the context of slowed down language development.

\section{STATEMENT OF PURPOSE}

The purpose of this thesis was to compare the usage of grammatical morphemes by three groups of four-year-old children: normal, language disordered, and those with a history of language delay but currently normal functioning. More specifically, this study attempted to determine whether language-disordered four-year-old children and those with a history of language delay have acquired a significantly lower percentage of selected grammatical morphemes than children of the same age with normal language skills.

The questions this study sought to answer were:

1. Which grammatical morphemes are acquired (used correctly in 90 percent of their required contexts) by four-year-old children with normal, disordered, and late developing language skills?

2. What are the percentages of use of grammatical morphemes by normal, language-disordered four- 
year-old children and those with a history of language delay?

3. Will language-disordered four-year-old children and those with a history of language delay have acquired a significantly smaller number of the 13 grammatical morphemes than children of the same age with normal language skills? That is, will significantly fewer morphemes be used with 90 percent accuracy?

The following null hypotheses were used to answer the questions:

1. There will be no difference among the three diagnostic groups in terms of the particular morphemes acquired (used with 90 percent accuracy in obligatory contexts).

2. There will be no significant difference in the percentage of usage of the grammatical morphemes among the three diagnostic groups.

3. There will be no significant difference in the number of morphemes acquired (used correctly in 90 percent of obligatory contexts) among the three diagnostic groups. 
Research hypotheses:

1. There will be a difference among the three diagnostic groups in terms of the particular morphemes acquired (used with over 90 percent accuracy in obligatory contexts).

2. There will be a significant difference in the percentage of usage of the grammatical morphemes among the three diagnostic groups.

3. There will be a significant difference in the number of morphemes acquired (used correctly in 90 percent of obligatory contexts) among the three diagnostic groups.

\section{DEFINITION OF TERMS}

The following operational definitions were employed for the purpose of the study.

1. Acquired morpheme: correct usage of a morpheme in 90 percent of obligatory contexts (Cazden, 1968; Brown, 1973).

2. Allomorph: variation in the pronunciation of a morpheme.

3. Articles: grammatical morphemes; a (indefinite: indicates a nonspecific referent and new information) and the (definite: indicates a specific referent and old information). 
4. Auxiliary be: verb to be which is obligatory with the present progressive morpheme and whose form varies with case, number, and tense. It may take the contractible form (cannot be contracted) as in "Who's crying? Baby is."

5. Bound morpheme: grammatical markers that must be attached to either free or other bound morphemes in order to have meaning.

6. Copula: verb to be used as a main verb to denote equivalence between subject and predicate. For example, as a contraction (the contractible form) "Papa's big." or the uncontractible form (cannot form a contraction) "Who's tired? I am."

7. Expressive lanquage-delayed children: children who produced fewer than 50 words at 20 to 34 months of age and who at age 4 had a mean length of utterance 1 standard deviation below the mean for chronological age (Miller, 1981).

8. Fourteen Grammatical Morphemes: morphemes identified by Brown (1973) as morphemes acquired with a large degree of regularity and chosen for their frequency of occurrence in speech and the ease with which their obligatory contexts could be identified. This study investigated usage of 13 of these morphemes. The irregular past was excluded due to constraints of the SALT 
computer program and a desire to eliminate the possibility of omitting any of its forms.

9. Free morpheme: autonomous morphemes that can form words or parts of words.

10. Grammatical morpheme: form words and inflections which represent small modifications in meaning.

11. History of language-delayed children: children producing fewer than 50 words at age 20 to 34 months of age but with an MLU within 1 standard deviation of the mean for chronological age at 48 to 59 months.

12. Late-talking toddlers: children who were originally placed in this group who produced fewer than 50 words at 20 to 34 months of age.

13. Mean length of utterance (MLU): an index of language development in which the number of morphemes in a language sample are divided by the number of utterances.

14. Morpheme: smallest meaningful unit of speech which cannot be divided without altering their meaning or yielding meaningless units.

15. Morphology: one of the five aspects of language involving rules that determine word organization and meaning .

16. Morphophoneme: sound changes that result from the joining of one morpheme with another. 
17. Normal-language children: children who produced 50 words or more at 20 to 34 months of age and who, at 48 to 59 months of age, had MLUs within 1 standard deviation of the mean for chronological age (Miller, 1981).

18. Past tense morpheme: bound morpheme attached to verbs to indicate an action that has already occurred, in regular form -ed.

19. Phonology: aspect of language involving rules that govern which sounds may occur, as well as the combination and ordering of those sounds.

20. Plural morpheme: bound morpheme attached to the ends of words to express number, generally $\mathbf{s}$.

21. Possessive morpheme: bound morpheme attached to the end of words to express possession, generally 's.

22. Present progressive morpheme: bound morpheme attached to verbs to indicate action that is presently occurring, generally - $\underline{\text { ing. }}$.

23. Third person singular morpheme: bound morpheme attached to verbs to indicate the third person singular form of the present tense verb, in regular form $\underline{s}$, as in "He sings." 


\section{REVIEW OF THE LITERATURE}

As research continues into the area of normal language development, more information becomes available regarding features that are acquired during the process. Once these features are established, performance of language-disordered children in these areas is examined. The results are then compared to determine whether certain features pose difficulties for the language-disordered child. One particular feature of language development under investigation is the use of grammatical morphemes. Grammatical morphemes are morphemes which may be bound or free and "represent functor words and inflections" (Steckol and Leonard, 1979, p. 291). According to Nicolosi, Harryman and Kresheck (1983), they "express subtle modulations in meaning rather than naming places, things or processes" (p. 51). Brown (1973) identified 14 grammatical morphemes that are acquired with a large degree of regularity. He defined acquisition of these morphemes as correct usage in 90 percent of required contexts. His choice of grammatical morphemes was based on their frequency of occurrence in speech and the ease 
with which their obligatory contexts (points at which the morphemes are required in adult speech) could be identified (Berko-Gleason, 1985). They are characterized by the following:

1. They are phonetically minimal forms (consist of simple phonemic constructions).

2. They are monosyllables or less and most often receive little stress.

3. They develop slowly.

4. They belong to a limited class of morphemes, unlike classes such as nouns which have a large membership and may expand in size.

It is the development of these 14 grammatical morphemes that is the focus of this study.

A discussion of the development of the 14 grammatical morphemes in normal and language-disordered children will be presented, including methodology used to assess their development. A brief description of the relationship between morphology and phonology will also be reviewed as this relationship may influence morpheme acquisition.

\section{GRAMMATICAL MORPHEMES}

Normal Development

Morphology refers to linguistic rules that govern word organization and meaning. A morpheme is the smallest 
meaningful unit of speech. It can be an entire word such as "learn" or the present progressive ending -ing. Thus the word "learning" contains two morphemes. Morphemes such as "learn" that can stand alone are called "free" morphemes. Those that contain no meaning unless attached to other morphemes are called "bound" morphemes.

Allomorphs are variations in pronunciation of morphemes, e.g., /s/ and /z/ which both express plurality when attached to nouns as in "cats" and "dogs."

Much of the research regarding morpheme development has arisen as a result of a study by Brown and his colleague Cazden (1968). Brown studied the acquisition of 14 grammatical morphemes in 3 children whom he followed longitudinally. Brown (1973) found a significant similarity among his subjects' order of acquisition of these morphemes. The children began using them at various times between two and three years of age and usage fluctuated from the time of their appearance to the time of acquisition. Acquisition was defined as correct usage of a grammatical morpheme in 90 percent of all obligatory contexts. This criterion for acquisition was adopted because usage in several consecutive speech samples leveled off between 90 and 100 percent after passing about the 90 percent level. 
The 14 grammatical morphemes studied by Brown are presented, in order of acquisition, in Table I. The present progressive morpheme - ing is used to indicate an

\section{TABLE I}

BROWN'S 14 GRAMMATICAL MORPHEMES IN ORDER OF ACQUISITION

$\begin{array}{lr}\text { Present progressive -ing } & \text { Daddy eating. } \\ \text { Prepositions: in } & \text { Toy in box. } \\ \text { on } & \text { Doll on table. } \\ \text { Regular plural -s } & \text { Blocks fall. } \\ \text { Irregular past } & \text { fell, went } \\ \text { Possessive -s } & \text { Momm's spoon. } \\ \text { Uncontractible copula } & \text { Who's away? He is. } \\ \text { Articles: a } & \text { I want a drink. } \\ \text { Regular past -ed } & \text { Eat the cookie. } \\ \text { Regular third person singular } & \text { Amy jumped in bed. } \\ \text { Irregular third person singular } & \text { Momy reads. } \\ \text { Uncontractible auxiliary } & \text { Who's watching? She is. } \\ \text { Contractible copula } & \text { Daddy is mad. Daddy's mad. } \\ \text { Contractible auxiliary Mommy is eating. Momm's eating. }\end{array}$

action currently in progress and of limited duration such as "She is crying." Initially the auxiliary verb is not used as in "She crying" (devilliers \& devilliers, 1973; Owens, 1984). In and on are two prepositions which express simple spatial relations (Owens, 1984). Young children have a lot of opportunities to use them at an early age. The plural $-\underline{s}$ morpheme occurs frequently and children learn early that it is used to distinguish between one and more than one. 
Irregular past tense is acquired before regular past, although at a later time the regular past ending is commonly overgeneralized to form verbs such as "falled" (Cazden, 1968; Owens, 1984). The possessive morpheme is used initially with animate nouns and progresses to include inanimate objects as well. The verb "be" is called a copula when used as a main verb. It signifies an equivalence relationship between the subject and predicate (e.g., He is thin.) or another noun (e.g., He is a plumber.). The uncontractible form (cannot be contracted, e.g., Who is old? She is.) is acquired earlier than the contractible form (which may take the form of a contraction, e.g., She's old.). The articles a and the often appear inconsistently early but are not acquired with 90 percent accuracy until later. While adults use the to indicate a specific referent and pragmatically to mark old information and $\underline{\text { a to }}$ to mark a nonspecific referent and new information, young children frequently overuse one article (Owens, 1984). Next, the regular past tense morpheme -ed is acquired. The only morpheme in English marking present tense is $-\underline{s}$ on the third person singular verb. The regular and irregular forms are acquired at about the same time and rule overgeneralization rarely occurs (Trantham \& Pedersen, 1976). The auxiliary verb be, also known as a helping verb, is obligatory with the -ing ending. The 
uncontractible form may not be contracted (e.g., "Who's sleeping? She is."), and is acquired prior to the contractible form, which may be used as a contraction (e.g., "Billy's shouting."). This is the last of the 14 grammatical morphemes to be acquired. The contractible copula is acquired sometime between the two auxiliary be forms.

Brown (1973) studied the language development of three preschool children. The children (whom Brown calls Eve, Adam and Sarah) were selected because they were (1) beginning to express themselves in multi-word utterances, (2) highly intelligible, and (3) extremely verbal. Eve was 18 months at the outset of the study while Adam and Sarah were 27 months old when they began. Spontaneous language samples were obtained on audiotape and transcribed from conversations between the children and their mothers at home. For five years, two hours of transcription were obtained every month for each child, except Eve who participated for only one year. subjects were matched by mean length of utterance in morphemes (MLU) and the longest utterance. MLU is calculated by dividing the total number of morphemes in a language sample by the total number of utterances. In order to make the data analysis more manageable, Brown divided developmental information into five approximately equal stages, defined by MLU ranges. Each stage was named 
either for a newly occurring developmental process or for a major development within a process. Brown's study suggested that an increase in MLU corresponded to an increase in utterance complexity, including an increase in use of grammatical morphemes. Table II displays Brown's stages of development, indexed by MLU.

\section{TABLE II}

BROWN'S STAGES OF PRESCHOOL LANGUAGE DEVELOPMENT

Stage Name $\underline{\text { MLU }}$

Age

$\begin{array}{rlll}\text { I } & \text { Telegraphic } & 1.0-2.0 & 12-26 \text { months } \\ \text { II } & \text { Grammatical Morphemes } & 2.0-2.5 & 27-30 \text { months } \\ \text { III } & \text { Basic Sentence Structure } & 2.5-3.0 & 31-34 \text { months } \\ \text { IV } & \text { Conjoining } & 3.0-3.75 & 35-40 \text { months } \\ \text { V } & \text { Embedding } & 3.75-4.5 & 41-46 \text { months }\end{array}$

He found that the order in which morphemes are acquired may be determined by semantic and syntactic complexity. Semantic complexity refers to the number of meanings within each morpheme. Syntactic complexity signifies the number of rules required when using each morpheme. For example, the regular plural morpheme is semantically less complex than the third person singular morpheme because it only denotes number while the latter includes number and person.

Development of the 14 grammatical morphemes begins in stage II when the child's MLU reaches 2.0. According to Brown (1973) present progressive, regular plural, and 
prepositional morphemes are acquired by approximately 30 months of age, possessives by 34 months, and regular third person singular by about 46 months of age. Many irregular past tense morphemes are acquired by 30 months but are later produced incorrectly when the regular past tense rule becomes overgeneralized. They are produced correctly again at around 46 months as are the regular past tense grammatical morphemes (Cazden, 1968; Owens, 1984). The uncontractible auxiliary and copulas are acquired by stage $V$, while the contractible auxiliary is not generally mastered until post stage $v$. Third person singular morphemes often appear in stage II but are not acquired until stage $\mathrm{V}$ (Owens, 1984).

As stated earlier, regular plurals are acquired by age two. According to Miller and Ervin-Tripp (1964), development of plurals occurs in four stages. In the first stage, plurals are not used at all. They appear in stage II. Moskowitz (1978) reports six stages for acquisition of plurals. The progression is essentially the same as that presented by Miller and Ervin-Tripp (1964). Irregular plurals take longer to acquire than regular plurals but will not be considered here because this study is only concerned with regular plurals.

Devilliers and devilliers (1973) confirmed Brown's findings indicating a predictability to grammatical 
morpheme development. Their study used 21 children between 16 and 40 months of age. Employing the same methods as Brown (1973), they replicated his results. Speech samples were collected, MLU was calculated, and the presence or absence of the 14 grammatical morphemes in obligatory contexts was tabulated. Both studies (Brown, 1973; devilliers \& devilliers, 1973) show a correlation between age and bound morpheme development and an even stronger relationship between language developmental level and morpheme production.

In summary, the development of the 14 grammatical morphemes for children with normal language skills is fairly well documented. In addition to a degree of predictability in their development, research indicates that there is a correlation between morpheme development and syntactic stage as indexed by MLU.

\section{Delayed Development}

Relatively little research has focused on the development of the 14 grammatical morphemes in children with specific language disorders. One such investigation was made by Johnston and Schery (1976). Their goal was to observe the use of grammatical morphemes by languageimpaired children and to compare these results to that reported by Brown (1973) and devilliers and devilliers (1973) for normal children. Language samples were 
obtained for 287 children ages $3.0-16.2$ who were enrolled in class for oral language disorders/aphasia. Included in the data reported were MLU and percentage of occurrence in obligatory contexts for the 14 grammatical morphemes. The data revealed a strong relationship between language level and grammatical morpheme usage. The language level at which each morpheme was acquired (90 percent use in obligatory contexts) was then compared to the performance of normal children. Although the language-disordered children were at higher language levels (i.e., MLUs) when morphemes were acquired, the order of morpheme acquisition was similar.

Similar findings were reported for two other investigations of grammatical morpheme development in language-disordered children. Kessler (1975) performed a longitudinal study of 18 language-disordered children ages 3.2-10.2. Her results showed a similar order of emergence of the 14 grammatical morphemes as reported by Brown (1973). Kessler did not report age or language level of acquisition. Trantham and Pederson (1976) also performed a longitudinal study of grammatical morpheme development by language-impaired children. Their research involved 8 children between the ages of 18 and 36 months, 1 of whom was language impaired. Unfortunately, the languageimpaired child did not acquire any of the morphemes by the 
study's end. Therefore, comparison of acquisition level and order of emergence data was not obtained. The results do suggest, however, that language-disordered children have difficulty acquiring these morphemes.

While these studies support earlier findings regarding grammatical morpheme development and give data on the performance of language-delayed children, a more systematic study would combine normal and language-delayed children while employing the same methods. Steckol and Leonard (1979) reported such an investigation. The study utilized 20 children. Ten children ranging in age from 34 to 47 months had normal language skills. Their performance was compared with that of 10 language-"deficient" children between ages 53 and 77 months. Diagnosis was based on standardized tests and, according to parental report, language-impaired subjects' one- and two-word utterances were delayed in comparison to the norm. None of the language-impaired subjects had organic etiologies. A speech sample for each subject was obtained using a picture description task. Subjects were matched based on MLU, and use of the 14 grammatical morphemes was analyzed. Although actual use of each morpheme was noted, only those morphemes used in at least five obligatory contexts by all subjects were analyzed, namely present progressive, articles, copula, and auxiliary. The data revealed that 
percentage of correct grammatical morpheme usage differed although MLU was the same. In support of previous research, grammatical morpheme usage was greater in normal subjects and order of emergence was similar for the two groups. The authors suggest that the reason MLU did not correspond with grammatical morpheme usage is because language-delayed children place less communicative value on them than normals, but this suggestion requires more research in order to substantiate it.

Another explanation for the difference in performance between normals and language-delayed children on grammatical morpheme usage is suggested in several studies (Leonard, 1989; Leonard, Sabbadini, Leonard, \& Volterra, 1987; Leonard, Sabbadini, Volterra, \& Leonard, 1988; Paul \& Shriberg, 1982). These researchers propose that the interaction between phonology and morphology may make a contribution. For this reason, a brief discussion of the relationship between morphology and phonology will be presented.

Relationship of Phonology to Morphological Development

Phonology is the study of sounds in language. All languages have a set of phonological rules that govern which sounds may occur, as well as the combination and ordering of those sounds. Phonetic development refers to the age at which the individual sounds of a language are 
produced correctly. The age of acquisition depends on the child's ability to make the motor configurations necessary to produce sounds. The entire phonetic inventory is normally acquired by age seven (Weiss, Gordon, \& Lillywhite, 1987).

Paul and Shriberg (1982) investigated the interaction between phonology and syntax in speech and languagedelayed children. Employing the 14 grammatical morphemes, they examined this relationship by dividing the morphemes into two groups based on morphophonemic complexity. Morphemes were considered complex if they required the addition of a consonant within a syllable. Language samples were analyzed according to several parameters. The results, of significance to the present study, showed that half of their subjects exhibited a limitation in their use of grammatical morphemes (complex morphophonemes) attributable to phonological complexity. Leonard, et al. (1987 and 1988), performed two studies based on the assumption that phonological constraints affect morpheme production which utilized Italian speaking subjects for comparison with Englishspeaking subjects. Many of the 14 grammatical morphemes were used in their investigation. Their results support the theory that phonological and phonetic factors contributed to deficits in morpheme usage. 
SUMMARY

Research by several investigators has revealed that children with specific language disorders have more difficulty with grammatical morpheme development than with sentence length as indexed by MLU. While languagedisordered children are behind their peers in terms of MLU, their grammatical morpheme development is even further behind than sentence length. Possible explanations for the difference between grammatical morpheme usage in normal and language-disordered children include the lack of communicative importance placed on grammatical morphemes by language-disordered children and phonologic abilities. Since the body of literature indicates delayed usage of grammatical morphemes by language-disordered children, it would be of interest to determine whether children with a history of expressive language delay will show grammatical morpheme deficits even when their MLU has progressed into the normal range. Further, identifying and examining which morphemes are delayed in both children with language disorders and those with a history of language delay will help to determine whether these children are functioning on a continuum or exhibiting distinct patterns of development. 
METHODS AND PROCEDURES

\section{SUBJECTS}

The 57 subjects who participated in this study were selected from 71 children currently participating in the Portland Language Development Project, a longitudinal study of language acquisition in late-talking children.

\section{Recruitment}

The subjects were initially recruited at approximately two years of age from pediatric clinics and radio and newspaper advertisements. Interested parents filled out a questionnaire and those who indicated interest in the study on the questionnaire were contacted. Parents of all subjects who participated in the study signed permission forms (Appendix A).

\section{Age 2 Group Placement}

The subjects were divided into two groups: latetalking toddlers (LT) and those with normal language development. The LT subjects produced fewer than 50 words between ages 20 and 34 months. The children determined to have a history of normal language development were 20 to 
34 months of age with an expressive vocabulary of more than 50 words. This information was obtained by parent report using the Lanquage Development Survey (LDS) (Rescorla, 1989) (Appendix B), a checklist of 300 of the most common words in children's early vocabularies. Rescorla (1989) reports the LDS to have high reliability and validity as a screening tool for identification of language delay for two-year-old children. Reliability was measured by test-retest techniques and Cronbach's alpha coefficients. Validity information included a high correlation between the LDS scores and performance of subjects on vocabulary tests such as Bayley, Reynell, and Preschool Language Scale.

Additional criteria for participation in the study required no known physical, mental, or other disability which might affect normal language development, passing a hearing screening at $25 \mathrm{~dB}$, and exhibiting normal intelligence by obtaining a score in the normal range on the Mental Development Index of The Bayley Scales of Infant Development. See Table III for demographic information.

\section{Age 4 Group Placement}

At age four, the children in the study were seen again individually. A spontaneous speech sample was obtained. 
TABLE III

SUMMARY OF DEMOGRAPHIC DATA

$\begin{array}{lllllrl}\text { Group } & \underline{n} & \text { Mean Age } & \text { Age Range } & \text { Sex Ratio F/M } & \text { SES } \\ \text { Normal } & 23 & 27 & \text { months } & 21-34 \text { months } & 10 \mathrm{~F} / 13 \mathrm{M} & 2.52 * \\ \text { Delayed } & 34 & 25.8 \text { months } & 20-33 \text { months } & 9 \mathrm{~F} / 25 \mathrm{M} & 2.73 *\end{array}$

* Based on a four-factor scale of 1 to 5 with 1 being the highest socio-economic status and 5 being the lowest.

The language samples were transcribed into a computer for analysis. MLU was calculated for each language sample by the Systematic Analysis of Language Transcripts (SALT) computer program (Miller \& Chapman, 1985). Subjects who were identified as normal at age two and whose MLUs at age four were within one standard deviation of expected levels for chronological age (Miller, 1981) were placed in the normal language group. Those children who were identified as LT at age two and who continued to exhibit delayed language development, as indexed by MLUs one standard deviation or more below the mean for chronological age (Miller, 1981), were assigned to the expressive language delay (ELD) group. Finally, any subjects who were identified at 20 to 34 months as LT but who showed MLUs to be within 1 standard deviation of the mean for chronological age at age 4 (Miller, 1981) were categorized in the history of expressive language delay (HELD) group (see Table IV). Subjects were placed within one of these three groups after all transcripts had been entered and 
analyzed, so this researcher was blind to the subjects' group assignment while data were being collected.

TABLE IV

GROUP PLACEMENT BASED ON MLU

Group $\underline{n}$ Mean Age Age Range Mean MLU (and s.d.)

Normal 234.1 months $4.0-4.10 \quad 4.37(0.609)$

ELD $\quad 15 \quad 4.3$ months $4.0-4.11 \quad 3.13(0.55)$

HELD $\quad 194.1$ months $4.0-4.2 \quad 4.44$ (1.59)

INSTRUMENTATION

The language samples collected at age four were audiotaped using a sony cassette tape recorder, a sony ECM-D8 electret condenser microphone and sony cassette tapes. Transcriptions of the language samples were entered into an IBM-compatible personal computer. As stated above, the SALT was employed to compute both MLU and percent usage of grammatical morphemes. SALT is a computer software program that analyzes morphological and semantic aspects of language (Miller \& Chapman, 1985). Once these data were obtained, SYSTAT, a computer software program for statistics, was used to perform an analysis of variance.

\section{PROCEDURES}

Spontaneous speech samples were audiotaped while each subject engaged in free play with their mother for 15 
minutes. The parent was instructed to "Play with your child as you do at home." Toys, including a house with people, furniture, cars, blocks, and play dishes were provided. Each language sample was transcribed by hand according to Miller's (1981) procedures.

The transcriptions were then entered into the SALT program with each grammatical morpheme's presence or absence in obligatory context coded into the data file. These data files for each transcript were checked against the original audiotapes by a second transcriber, both for accuracy of transcription and for correct morpheme codes.

\section{DATA ANALYSIS}

SALT was then employed to determine (1) MLU (an index of language development calculated by dividing the total number of morphemes in each language sample by the total number of utterances), (2) the percentage of usage of grammatical bound morphemes in obligatory contexts, and (3) the number of grammatical free morphemes which did and did not occur in obligatory contexts for each language sample. Then the percentage of usage of the free morphemes was calculated by hand for each subject. The irregular past grammatical morpheme was omitted from this study due to limitations of the SALT program and to make 
certain that no morpheme in each category would be erroneously left out. Thus, only 13 of Brown's 14 morphines are analyzed in this study.

As stated above, a one-way analysis of variance (ANOVA) was performed using SYSTAT to determine whether a difference existed among the three experimental groups (normal, ELD, and HELD) in terms of the percentage of use in obligatory context for each of the 13 grammatical morphemes.

\section{Reliability}

Graduate students in the speech and Hearing Sciences Department were trained in data entry as specified by the SALT program. All language samples, once entered, were rechecked for accuracy. Ten transcripts were selected at random for the purpose of determining reliability. This investigator listened to the language sample tapes and compared them to the hand-transcribed version of another trained graduate student. Inter-rater reliability for words was found to be 97 percent. 
CHAPTER IV

RESULTS AND DISCUSSION

RESULTS

The purpose of this study was to determine whether a significant difference exists in the percentage of usage of 13 grammatical morphemes among three groups of fouryear-old children: normal, ELD, and HELD.

The questions asked by this study were:

1. Which grammatical morphemes are acquired (i.e., used with 90 percent accuracy) by four-year-old children with normal, disordered, and late developing language skills?

2. What are the percentages of usage of grammatical morphemes by normal, language-disordered fouryear-old children and those with a history of language delay?

3. Will language-disordered four-year-old children and those with a history of language delay have acquired a significantly smaller number of 13 grammatical morphemes than children of the same age with normal language skills? 
In answer to the first question, the morphemes which have been acquired by each group are presented in Table $V$.

\section{TABLE V}

\section{LIST OF MORPHEMES ACQUIRED BY} EXPERIMENTAL GROUPS

\section{Normal}

Present progressive

Prepositions

Regular plural

Possessive

Uncontractible copula

Articles

Regular past

Regular third person singular

Irregular third person singular

Uncontractible auxiliary be

Contractible copula

(All but the contractible auxiliary be.)

\section{$\underline{E L D}$}

Present progressive

Prepositions

Regular plural

Possessive

\section{HELD}

Present progressive

Prepositions

Regular plural

Possessive

Uncontractible copula

Articles

Regular past

Contractible copula

The mean percentage of usage of each of the 13

grammatical morphemes for each group (question two) are presented in Table VI. 


\section{TABLE VI}

PERCENTAGE OF USAGE OF 13 GRAMMATICAL MORPHEMES BY THREE GROUPS OF FOUR-YEAR-OLD CHILDREN

$\begin{array}{lrrr} & \text { Normal } & \text { ELD } & \text { HELD } \\ & (\mathrm{n}=23) & (\mathrm{n}=19) & (\mathrm{n}=15) \\ \text { Present progressive -ing } & 100.00 \% & 96.56 \% & 99.28 \% \\ \text { Prepositions: in } & 95.12 & 92.30 & 97.10 \\ \text { on } & 98.21 & 100.00 & 100.00 \\ \text { Regular plural -s } & 98.73 & 91.11 & 94.54 \\ \text { Possessive -s } & 90.97 & 82.50 & 100.00 \\ \text { Uncontractible copula } & 95.07 & 85.70 & 93.61 * \\ \text { Articles: a } & 95.11 & 86.53 & 91.12 \\ \text { Regular past -ed } & 97.38 & 88.37 & 92.40 \\ \text { Regular third person singular } & 100.00 & 85.88 & 97.50 \\ \text { Irregular third person singular } & 94.20 & 80.46 & 77.01 \\ \text { Uncontractible auxiliary be } & 93.13 & 42.50 & 87.50 * \\ \text { Contractible copula } & 92.85 & 68.75 & 86.90 * \\ \text { Contractible auxiliary be } & 95.51 & 82.99 & 92.33 \\ & 87.55 & 68.78 & 84.34 *\end{array}$

* Denotes morphemes showing a significant difference in usage based on the ANOVA.

The results of the one-way ANOVA, including the source (between and within groups), the total sum of squares, degrees of freedom, F-ratio (variance ratio), and $P$ (significance level) are displayed in Table VII.

Four morphemes, namely irregular third person singular, uncontractible copula, and contractible and uncontractible auxiliary were used significantly differently among the three groups (Table VII). In all cases the ELD group's usage was significantly lower than normals. The HELD group had failed to acquire three morphemes that were acquired by normals: regular and irregular third person singular and uncontractible auxiliary be. 
TABLE VII

ANOVA

Source Sum-of-Squares DF Mean-Squared F-Ratio $\underline{P}$

$\underline{A}$

$\begin{array}{lrrrrr}\text { Group } & 227.878 & 2 & 113.939 & 0.368 & 0.694 \\ \text { Error } & 16705.012 & 54 & 309.352 & & \end{array}$

Contractible Auxiliary be

$\begin{array}{lcrrrr}\text { Group } & 3772.53 & 2 & 1886.268 & 3.937 & 0.026 * \\ \text { Error } & 24916.216 & 52 & 479.158 & & \end{array}$

Contractible copula

Group

Error

Group

Error

Group

Error

Group

Error

Group

Error

Group

Error

Group

Error
1941.659
10853.660

2
4

1785.714

1250.000

In
$1.429 \quad 0.34$

0.353

0.705

$14340.659 \quad 52 \quad 275.782$

Present progressive -ing

$\begin{array}{rrrrr}103.477 & 2 & 51.739 & 2.995 & 0.059 \\ 846.498 & 49 & 17.275 & & \end{array}$

Irregular Third Person Singular

20756.881

50040.250

$\begin{array}{rr}2 & 10378.441 \\ 45 & 1112.006\end{array}$

9.333

$0.0 *$

$\underline{\text { on }}$

$\begin{array}{rrr}28.195 & 2 & 14.098 \\ 580.357 & 35 & 16.582\end{array}$

0.850

0.436

\section{Regular Past -ed}

$\begin{array}{rrrrr}779.661 & 2 & 389.831 & 0.640 & 0.534 \\ 20708.879 & 35 & 609.085 & & \end{array}$

Plural -s

$\begin{array}{rrr}770.528 & 2 & 385.264 \\ 8158.711 & 53 & 153.938\end{array}$

2.503

0.091 


\section{TABLE VII \\ ANOVA \\ (continued)}

Source Sum-of-Squares DF Mean-Squared F-Ratio $\underline{P}$

\section{Possessive - s}

$\begin{array}{lcrrrr}\text { Group } & 1173.53 & 2 & 586.727 & 0.667 & 0.517 \\ \text { Error } & 21653.940 & 25 & 866.158 & & \end{array}$

Regular Third Person Singular

$\begin{array}{lrrcrr}\text { Group } & 2833.573 & 2 & 1416.787 & 2.287 & 0.113 \\ \text { Error } & 29733.364 & 48 & 619.45 & & \end{array}$

The

$\begin{array}{lrrlrr}\text { Group } & 853.360 & 2 & 426.68 & 1.445 & 0.245 \\ \text { Error } & 15944.863 & 54 & 295.275 & & \end{array}$

Uncontractible Auxiliary be

Group

7390.273

$2 \quad 3695.136$

4.139

$0.026 *$

Error 26784.089

30

892.803

Uncontractible copula

$\begin{array}{lrrrrr}\text { Group } & 799.478 & 2 & 399.739 & 1.415 & 0.0252 * \\ \text { Error } & 14694.531 & 52 & 282.587 & & \end{array}$

* Denotes morphemes showing a significant difference in usage.

\section{DISCUSSION}

This investigation sought to compare the usage of grammatical morphemes by three groups of four-year-old children: normal, language disordered, and those with a history of language delay but currently normal functioning. The research hypotheses proposed that the language-disordered four-year-old children and those with 
a history of language delay would have more difficulties in acquiring these 13 grammatical morphemes than children of the same age with normal language skills. For the purpose of discussing the results of this study, Table VIII presents the stage assignments given by Brown (1973) for his normal subjects for each of the grammatical morphemes.

TABLE VIII

STAGE ASSIGNMENT FOR NORMAL GRAMMATICAL MORPHEME DEVELOPMENT

stage Morpheme

$\underline{\text { MLU }}$

Age

II $\begin{array}{llll}\text { plural } & 2.0 & -2.5 & 12-26 \\ \text { in months }\end{array}$

III on

$2.5-3.0 \quad 27-30$ months

possessive
$\mathrm{V}$ regular past -ed $\quad 3.75-4.5 \quad 41-46$ months articles
regular third person
singular
contractible copula

V+ contractible auxiliary be
uncontractible copula
uncontractible auxiliary be
irregular third person

singular

Looking at the percentage of usage of the 13

grammatical morphemes based on the 90 percent acquisition

criteria reveals some interesting trends. The four

earliest acquired grammatical morphemes, namely present progressive, prepositions (in and on), and regular plurals 
were acquired by all three groups of children. The possessive, uncontractible copula, articles (a and the), and regular past morphemes (which are normally acquired next) had been acquired by the subjects with normal language skills and the HELD group, but they had not been acquired by the ELD group. Acquisition of the contractible copula morpheme had been achieved by both the normal and HELD groups. Regular and irregular third person singular and uncontractible auxiliary were acquired by the children from the normal language skill group only. And finally, the contractible auxiliary morpheme normally acquired last had not been acquired by any of the groups, although usage for the normal group ( 87.05 percent) indicates it is very close to the acquisition criteria. According to age level expectations for language development, all of the grammatical morphemes should have been acquired by children with normal language skills. Morpheme usage of the normal subjects in this study are basically consistent with this standard. The ELD subjects are clearly delayed as they have acquired only four of the morphemes. They have, though, acquired morphemes in the order seen in the other studies cited in the literature review. Although the HELD subjects have acquired more of the grammatical morphemes (ten in all) than the ELD group, their usage is still delayed when compared with normal 
acquisition. They have not yet acquired regular and irregular third person singular and the contractible and uncontractible auxiliary be.

Comparison of grammatical morpheme acquisition with MLU also provides important information. The mean MLU for the ELD subjects is 3.13 with a standard deviation of .55 . This places them in Brown's (1973) stage IV. According to research (devilliers \& devilliers, 1973), these subjects should have acquired the present progressive, regular plural, prepositions, and the possessive morphemes.

Because the ELD subjects have not acquired the possessive morpheme, their grammatical morpheme acquisition is below expected performance for MLU. The HELD group with a mean MLU of 4.4 should have acquired all morphemes through stage $V$ and possibly more since the standard deviation is 1.59. While these subjects have acquired the copula (post stage $V$ ), they have not yet acquired the regular third person singular (77.01 percent). As with the ELD group, grammatical morpheme acquisition is slightly below the expected level based on MLU. The difference between grammatical morpheme development for the HELD subjects is highlighted when looking at morpheme acquisition for the normal group. The mean MLU for normals in this study is 4.37 with a standard deviation of .609. This places them in stage $\mathrm{V}-\mathrm{V}+$. But in fact, they have acquired almost all 
of the grammatical morphemes. These results are similar to those found by the steckol and Leonard (1979) study in which language-delayed children matched by MLU with normals used fewer of the grammatical morphemes.

In summary, a consistent order in acquisition of grammatical morpheme usage appears among all three groups. Normals have reached acquisition criterion on the largest number of grammatical morphemes, and HELD subjects acquired fewer than normals but more than languagedisordered subjects. These results suggest that ELD children, as predicted, show some deficits in grammatical morpheme acquisition over and above their generally depressed expressive language skills. Further, HELD children have difficulty acquiring these morphemes too, and their acquisition is delayed, even when sentence. length, as indexed by MLU, has progressed into the normal range. These data can be interpreted to suggest that children with a history of language delay do function on a continuum rather than exhibit a distinct pattern of development.

It still remains to be determined why these differences occur. Paul and Shriberg's (1982) hypothesis that it is the phonetically complex morphemes that are delayed is not supported by these findings. Phonetically complex morphemes such as plurals, possessives, and contractible 
copula are not different among the groups, while phonetically simple ones such as uncontractible auxiliary and copula be are different. Unfortunately, the data does not reveal the answer, and any solution can only be hypothesized. Perhaps as Steckol and Leonard (1979) theorized, language-disordered children place less attention on grammatical morphemes because of their relatively low communicative value. Further research is necessary before any conclusions may be drawn. 


\section{CHAPTER V}

\section{SUMMARY AND IMPLICATIONS}

\section{SUMMARY}

The purpose of this study was to determine whether language-disordered four-year-old children and those with a history of language delay but currently normal functioning would have acquired a significantly lower percentage of 13 grammatical morphemes than children of the same age with normal language skills. Research has shown that there is a consistency of order in which these morphemes are acquired in children with normal language ability. Studies have also shown that while language-disordered children acquire these grammatical morphemes in a similar order, the process is slowed down. Language-disordered children have difficulty with grammatical morpheme development. Not found in the research is information regarding grammatical morpheme development for children with normal language skills but a history of language delay. Does grammatical morpheme development still pose a problem for these children? Is grammatical morpheme development for this population consistent in terms of order of acquisition with normal and language-disordered children? 
Does acquisition of these morphemes still show deficiencies when language skills have progressed into the normal range? Do patterns of grammatical morpheme development demonstrate distinct features for these children? These are the questions that the present investigation sought to answer.

The sample for this study comprised 57 4-year-old children participating in a longitudinal study at Portland State University. They were divided into three groups: children with normal language skills, a history of expressive language delay, and expressive language disordered. Language samples were obtained for each subject while engaged in play with their mother. The samples were transcribed and entered into a computer at which time the SALT (Miller \& Chapman, 1985) program calculated MLU for group placement. Percentage of usage of the grammatical morphemes in obligatory contexts was then determined, again employing SALT. Where necessary, percentages were totalled by hand. An analysis of variance was then performed using SYSTAT. The results showed four morphemes to be significant at the .03 level--irregular third person singular, uncontractible copula, and contractible and uncontractible auxiliary be.

Investigation of the data suggests that there is a uniformity in order to acquisition of the grammatical 
morphemes similar to past research, and percentage of usage of these morphemes for the HELD group was larger than the ELD group but smaller than the normal group. This indicates that while children with a history of language delay have progressed into the normal range for sentence length as indexed by MLU, they still have difficulty with grammatical morpheme development. In conclusion, these results suggest that children with a history of language delay but who are currently normal functioning do lie on a continuum of language ability between language-disordered and normal children.

\section{IMPLICATIONS}

\section{Clinical}

As stated earlier, morphology is an important aspect of language and language assessment. Clearly, the results of this study, as well as past research, demonstrate that MLU should not be used as the only measure of morphological language skills. Children can have MLUs within the normal range but also exhibit grammatical morpheme deficits. Assessment of percentage of usage of grammatical morphemes would be more accurate, and, if a child has been selected to receive language remediation services, this information can be used as a guideline for determining client objectives--not only in terms of which morphemes 
should be targeted for intervention (those which have not reached the acquisition criteria level) but also the order in which they should be included in remediation based on the order of acquisition as reported in past research and supported by this investigation. Additionally, the data provide information regarding prognosis for ELD children. Two-year-old children with an expressive language delay may improve in some areas of language (in this case sentence length as indexed by MLU) but still exhibit deficits in other areas which may signal a need for intervention.

\section{$\underline{\text { Research }}$}

Further research regarding grammatical morpheme development for these three groups needs to be done. It would increase our knowledge base in morphological development if a longitudinal and/or follow-up study were performed in which the age and level of language abilities were obtained for when each morpheme is acquired. In agreement with earlier research, this study revealed that MLU did not completely correspond with grammatical morpheme usage in children with histories of language problems. Additional research is necessary to determine whether this occurred because language-delayed children place less importance on grammatical morphemes or for some other reason. Finally, division of the data for subjects obtained in this study as indicated by phonological 
development may provide information regarding the relationship between morphophonemic complexity and deficits in grammatical morpheme usage. 
REFERENCES

Berko-Gleason, J. (1985). The development of language. Columbus, $\mathrm{OH}$ : Charles E. Merrill.

Brown, R. (1973). A first language: The early stages. Cambridge, MA: Harvard University Press.

Cazden, C. (1968). The acquisition of noun and verb inflections. Child Development, 39, 433-448.

devilliers, J.G., and devilliers, P.A. (1973). A cross sectional study of the acquisition of grammatical morphemes in child speech. Journal of Psycholinguistic Research, $\underline{2}, 267-278$.

devilliers, J.G., and devilliers, P.A. (1978). Language acquisition. Cambridge, MA: Harvard University Press.

Johnston, J., and Schery, T. (1976). The use of grammatical morphemes by children with communicative disorders. In D. Morehead and A. Morehead (eds.) Normal and deficient child language (pp. 239-258). Baltimore, MD: University Park Press.

Kessler, C. (1975). Postsemantic processes in delayed child language related to first and second language learning. In D. Dato (ed.) Georgetown University round table on language and linquistics. Washington, DC: Georgetown University Press.

Klee, T., and Fitzgerald, M.D. (1985). The relation between grammatical development and mean length of utterance in morphemes. Journal of Child Language, $\underline{12}(2), 251-269$.

Leonard, L.B. (1989). Language learnability and specific language impairment in children. Applied Psycholinguistics, 10, 179-202.

Leonard, L.B., Sabbadini, L., Leonard, J.S., and Volterra, V. (1987). Specific language impairment in children: A cross-linguistic study. Brain and Lanquage, 32, $233-252$. 
Leonard, L.B., Sabbadini, L., Volterra, V., and Leonard, J.S. (1988). Some influences on the grammar of English- and Italian-speaking children with specific language impairment. Applied Psycholinguistics, 9 , $39-57$.

Meline, T.J., and Meline, N.C. (1981). Normal variation and prediction of mean length of utterance from chronological age. Perceptual and Motor skills, 53, $376-378$.

Miller, J.F. 91981). Assessing language production in children. Austin, TX: PRO-ED.

Miller, J.F., and Chapman, R.S. (1981). The relation between age and mean length of utterance in morphemes. Journal of Speech and Hearing Research, 29, 154-161.

Miller, J., and Chapman, R. (1985). Systematic analysis of language transcripts: User's manual. Madison, WI: University of Wisconsin.

Miller, W., and Ervin-Tripp, S. (1964). The development of grammar in child language. In U. Bellugi and $R$. Brown (eds.) The acquisition of language. Monographs of the Society for Research in Child Development, 92 .

Moskowitz, B. (1977). The acquisition of language. Scientific American, Nov., 239, 92-108.

Nicolosi, L., Harryman, E., and Kresheck, J. (1983). Terminology of communication disorders (2nd ed.). Baltimore, MD: Williams \& Wilkins.

Owens, R.E., Jr. (1986). Communication, language, and speech. In G.H. Shames and E.H. Wiig (eds.) Human communication disorders (2nd ed.) (pp. 27-79), Columbus, $\mathrm{OH}$ : Charles E. Merrill.

Owens, R.E., Jr. (1984). Lanquage development: An introduction. Columbus, $\mathrm{OH}$ : Charles E. Merrill.

Paul, R., and Shriberg, I.D. (1982). Associations between phonology and syntax in speech-delayed children. Journal of Speech and Hearing Research, 25, 536-547.

Pinker, S. (1985). Lanquage learnability and language development. Cambridge, MA: Harvard University Press. 
Rescorla, L. (1989). The language development survey: A screening tool for delayed language in toddlers. Journal of Speech and Hearing Disorders, 54, 587-597

Rondal, J.A., Ghiotto, M., Bredart, S., and Bachelet, J. (1987). Age, relation, reliability and grammatical validity of measures of utterance length. Journal of Child Language, $\underline{4}(3), 433-446$.

Scarborough, H., Wyckoff, J., and Davidson, R. (1986). A reconsideration of the relation between age and mean utterance length. Journal of Speech and Hearing Research, $\underline{29}(3), 394-399$.

Steckol, K.F., and Leonard, L.B. (1979). The use of grammatical morphemes by normal and language-impaired children. Journal of Communication Disorders, 12, 291-301.

Trantham, C., and Pederson, J. (1976). Normal language development. Baltimore, MD: Williams \& Wilkins.

Weiss, C.E., Gordon, M.E., and Lillywhite, H.S. (1987). Clinical management of articulatory and phonological disorders. Baltimore, MD: Williams \& Wilkins. 
APPENDIX A

PARENTAL CONSENT FORM 


\section{INFORMED CONSENT}

I, hereby agree to serve

as a subject in the research project on language development in young children conducted by Rhea Paul.

I understand that the study involves seeing my child yearly for speech and language evaluation and videotaping conversations between me and my child. I understand that these tapes will be transcribed for analysis of my child's spoken language patterns.

It has been explained to me that the purpose of the study is to learn whether children who begin talking late are at risk for later learning problems.

I may not receive any direct benefit from participation in this study, but my participation may help to increase knowledge which may benefit others in the future.

Dr. Paul has offered to answer any questions I may have about the study and what is expected of me in the study. I have been assured that all information I give will be kept confidential and that the identity of all subjects will remain anonymous.

I understand that I am free to withdraw from participation in this study at any time without jeopardizing my relationship with portland state University.

I have read and understand the foregoing information.

Date Signature

If you experience problems that are the result of your participation in this study, please contact the secretary of the Human Subjects Research and Review Committee, office of Grants and Contracts, 303 cramer Hall, Portland State University, 464-3417. 
APPENDIX B

LANGUAGE DEVELOPMENT SURVEY 
VOCABULARY CHECK:15T

Please circle each word your child says. Don't include words your chilo can understano but not say. Il's ok to count words that aren't pronounced clearly. If your child speaks a foreign lanouage. please check off Englisn versions of the words he uses.

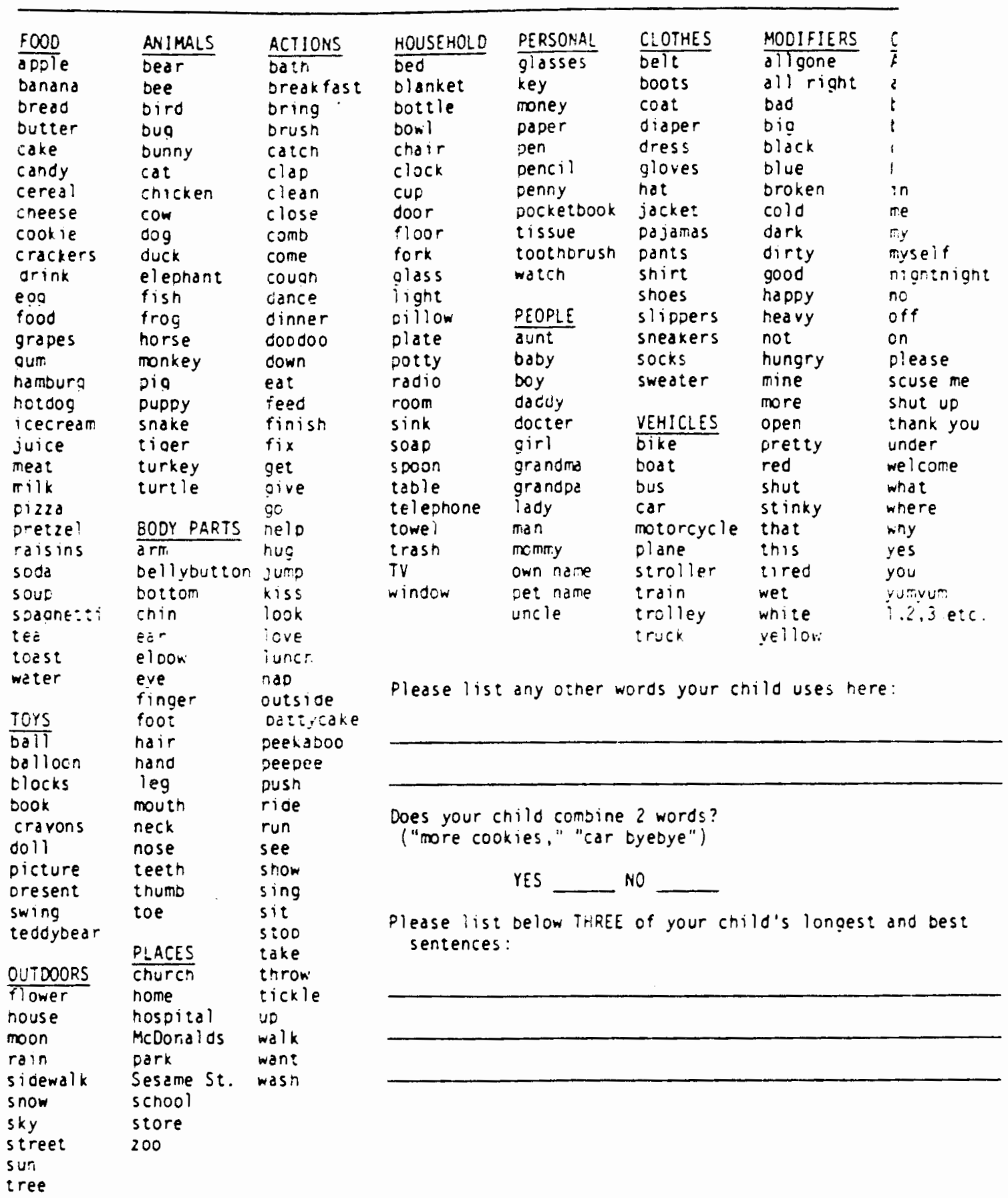

